\title{
Gold nanoparticle-based fluorescence quenching via metal coordination for assaying protease activity
}

\author{
Se Yeon Park • So Min Lee • Gae Baik Kim • \\ Young-Pil Kim \\ Published online: 25 October 2012 \\ (C) The Author(s) 2012. This article is published with open access at SpringerLink.com
}

\begin{abstract}
We report a gold nanoparticle (AuNP)-based fluorescence quenching system via metal coordination for the simple assay of protease activity. Carboxy AuNPs (5 nm in core diameter) functioned as both quenchers and metal chelators without requiring further modification with multidentate ligands; therefore, they were strongly associated with the hexahistidine regions of dye-tethered peptides in the presence of $\mathrm{Ni}(\mathrm{II})$ ions, leading to notable fluorescence quenching over the varying molar ratios of dye to AuNP. Upon the addition of matrix metalloproteinase-7 (MMP-7), the fluorescent intensity was efficiently recovered in one-pot mixture especially at 10:1-100:1 molar ratios of dye to AuNP. Consequently, the dequenching degree was dependent on the MMP-7 concentration in a hyperbolic manner, ranging from as low as 10 to $1,000 \mathrm{ngmL}^{-1}$. In this regard, we anticipate that the developed system will give us a general way to construct nanoparticle-dye conjugates and will find applications in the analyses of many other proteases mediating significant biological processes with low background and high sensitivity.
\end{abstract}

Se Yeon Park, So Min Lee and Gae Baik Kim contributed equally to this work.

S. Y. Park

Department of Chemical Engineering, Hanyang University,

Seoul 133-791, South Korea

S. M. Lee

Department of Bio Engineering, Hanyang University,

Seoul 133-791, South Korea

G. B. Kim • Y.-P. Kim $(\bowtie)$

Department of Life Science, Hanyang University,

Seoul 133-791, South Korea

e-mail: ypilkim@hanyang.ac.kr

G. B. Kim • Y.-P. Kim

Research Institute for Natural Sciences, Hanyang University,

Seoul 133-791, South Korea
Keywords Gold nanoparticle · Quenching · Metal coordination $\cdot$ Protease $\cdot$ Matrix metalloproteinase

\section{Introduction}

The interactions between gold nanoparticles (AuNP) and organic dyes have gained considerable interest in biochemical assay because they provide many advantages regarding quenching efficiency and photostability over the classical dye quencher system [1-6]. The ability of AuNPs to induce fluorescence quenching of proximal dyes is reported to be directed by a surface energy transfer process [7-9]; the rate of energy transfer from a dye to AuNP depends on the inverse of fourth power of the donor-acceptor separation, which triggers a much longer working distance (up to $22 \mathrm{~nm}$ ) than that observed in a traditional fluorescence resonance energy transfer system (up to $10 \mathrm{~nm}$, due to the inverse sixth power distance dependency). To this end, AuNP-organic dye couples have been implemented for the highly sensitive detection of oligonucleotides [10-12], proteins [13-17], and other small molecules [18-20].

Recently, the activities of enzymes such as proteases and nucleases have also been analyzed using activatable "switch-on" fluorescent nanoprobes in order to gain some insight into enzyme kinetics or biological activity [21-23]. In particular, proteases have been recognized as important targets due to their roles that are involved in multiple processes during malignant progression, including tumor angiogenesis, invasion, and metastasis [24, 25]. Proteasedetecting methods, therefore, have been accomplished by incorporating relatively stable peptides between the AuNP and the dye via either biotin-avidin interaction $[22,26]$ or thiol-mediated coupling [27-29]. In addition to these conjugations, nickel-nitrilotriacetic acid (Ni(II)-NTA)modified AuNPs were recently demonstrated by several groups $[30,31]$ since $\mathrm{Ni}(\mathrm{II})-\mathrm{NTA}$ provides high binding 
affinity $\left(K_{\mathrm{d}}=10^{-13} \mathrm{M}\right)$ for a hexahistidine tag at $\mathrm{pH} 8.0$ [32], which has been widely used as one of the most useful affinity methods. However, these $\mathrm{Ni}$ affinity nanoconjugates have been only limited to capture or label proteins with polyhistidine tags, and there was little attempt for enzyme activity study. As an alternative, to enable an easy surface modification based on $\mathrm{Ni}$ affinity, Rao's group reported that NTA-free carboxy quantum dot (QD) could be conjugated to his-tagged luciferases in the presence of nickel ions, which developed a QD-bioluminescence resonance energy transfer system to assay protease activity [33]. On the basis of this observation, we envisioned that the use of his-tagcontaining peptide affinity tag would allow a sitespecific and multivalent conjugation to carboxy AuNPs and would generate a shorter distance between the AuNP and the organic dye, which is favorable for higher energy transfer efficiency regime than that of the biotin-avidin strategy.

Here, we demonstrate a simple fluorescence quenching system using carboxy AuNPs and dye-conjugated peptides and its application to protease assay. A facile conjugation of a dye-coupled peptide to the carboxy AuNP was made possible in the presence of $\mathrm{Ni}$; the resultant AuNP-dye conjugate via metal affinity was used for the detection of matrix metalloproteinase (MMP) activity. We chose MMP as a model protease because MMPs play a crucial role in a wide variety of processes including tumor metastasis, inflammation, growth differentiation, and cell signaling [34-36]. To achieve the optimal fluorescence quenching and dequenching system by protease activity, the quenching efficiency and protease-induced recovery yield of AuNPs toward an organic dye (5(6)-carboxytetramethylrhodamine, TAMRA) was compared in terms of the dye-to-AuNP ratio. Details are reported herein.

\section{Experimental section}

\section{Materials}

Nickel(II) chloride hexahydrate $\left(99.9 \%, \mathrm{NiCl}_{2} \cdot 6 \mathrm{H}_{2} \mathrm{O}\right)$, hydrogen tetrachloroaurate(III) trihydrate $\left(99.9 \% \mathrm{HAuCl}_{4} \cdot 3 \mathrm{H}_{2} \mathrm{O}\right)$, sodium citrate dihydrate (trisodium salt, $\mathrm{C}_{6} \mathrm{H}_{5} \mathrm{Na}_{3} \mathrm{O}_{7} \cdot 2 \mathrm{H}_{2} \mathrm{O}$ ), and sodium borohydride $\left(99 \%, \mathrm{NaBH}_{4}\right)$ were purchased from Sigma-Aldrich. Carboxy- $\mathrm{PEG}_{12}$-thiol and methyl- $\mathrm{PEG}_{4}$-thiol were purchased from Thermo Scientific. Active matrix metalloproteinase-7 (MMP-7) enzyme was purchased from Merck4Biosciences. The TAMRA-labeled peptide (TAMRAGPLGMRGLHHHHHH) was synthesized from Peptron, Inc. (Korea). All chemicals were of analytical grade and were used as received.
Synthesis of AuNPs

AuNPs were synthesized by reduction and stabilization with citrate. Briefly, $100 \mu \mathrm{L}$ of a stock solution containing $300 \mathrm{mM}$ of $\mathrm{HAuCl}_{4} \cdot 3 \mathrm{H}_{2} \mathrm{O}$ was added to $100 \mathrm{~mL}$ of distilled water to give a final concentration of $300 \mu \mathrm{M}$ followed by vigorous stirring. To this solution, $2 \mathrm{~mL}$ of $30 \mathrm{mM}$ sodium citrate dihydrate was added at a final concentration of $600 \mu \mathrm{M}$ (the molar ratio of tetrachloroaurate to sodium citrate is 1:2) and stirred. For the fast reduction and formation of gold colloids, $100 \mu \mathrm{L}$ of a stock solution containing $300 \mathrm{mM}$ of $\mathrm{NaBH}_{4}$ was quickly added to the reaction solution followed by stirring. The clustering of AuNPs was checked by UV-Visible spectroscopy (Cary $60 \mathrm{UV}-\mathrm{Vis}$, Agilent Technologies), and the average size of AuNPs was estimated to be $5.1 \pm 1.4 \mathrm{~nm}$ $(n=100)$ using a field emission transmission electron microscope (FE-TEM; FEI Tecnai G2F30S-TWIN, the Netherlands). Surface modification of the synthesized AuNPs was performed with the 1:1 mixture of methyl- $\mathrm{PEG}_{4}$-thiol and carboxy-PEG 12 -thiol (total, $100 \mu \mathrm{M}$ ), which was added to the citrate-stabilized AuNP solution (final, $50 \mathrm{nM}$ ). Since the used 5-nm AuNP is estimated to have 3,858 Au atoms in total and $984 \mathrm{Au}$ atoms at its surface based on the reported calculation method [37, 38], the 2,000:1 ligand-to-AuNP molar ratio was used to ensure the complete surface modification of AuNPs. After $2 \mathrm{~h}$ of incubation under convection, the carboxy-modified AuNPs were purified using an Amicon ${ }^{\circledR}$ Ultra Centrifugal Filter Unit (50 kDa, MWCO) and centrifugation $(8,000 \times \mathrm{g}$ for $10 \mathrm{~min})$. The final concentration of the AuNPs in solution was calculated using the molar extinction coefficient $\left(1.2 \times 10^{7} \mathrm{M}^{-1} \mathrm{~cm}^{-1}\right)$ at $520 \mathrm{~nm}$.

\section{Analysis of fluorescence quenching}

For quenching experiments, the TAMRA peptide $(2.5 \mu \mathrm{L}$ at $10 \mu \mathrm{M})$ was mixed with varying amounts of carboxy AuNPs $(2.5-25 \mu \mathrm{L}$ at $1 \mu \mathrm{M})$ at a $100: 1-1: 1$ ratio of the TAMRA peptide and AuNP in the absence or presence of $\mathrm{NiCl}_{2}(10 \mu \mathrm{L}$ at $1 \mathrm{mM})$. All reactions were performed at a final volume of $100 \mu \mathrm{L}$ in $20 \mathrm{mM}$ Tris buffer (pH 7.5) at RT. After $30 \mathrm{~min}$ of incubation, the fluorescence spectra were measured at an excitation wavelength of $550 \mathrm{~nm}$ using a spectrofluorometer (FS-2, Sinco, South Korea). We initially tested the self-quenching and detection range of the TAMRA-conjugated peptide. Self-quenching was significant at more than $10 \mu \mathrm{M}$ TAMRA; therefore, the final concentration of the TAMRA-conjugated peptide in this study was determined to be $250 \mathrm{nM}$.

\section{Protease assay}

In a one-pot method, AuNPs $(2.5$ or $5 \mu \mathrm{L}$ at $1 \mu \mathrm{M})$, TAMRA peptide $(2.5 \mu \mathrm{L}$ at $10 \mu \mathrm{M}), \mathrm{NiCl}_{2}(10 \mu \mathrm{L}$ at 
$1 \mathrm{mM})$, and MMP-7 protease $(10 \mu \mathrm{L}$ at different stock concentrations) were mixed at a time in $20 \mathrm{mM}$ Tris buffer (pH 7.5) to give a final volume of $100 \mu \mathrm{L}$ and incubated at $37^{\circ} \mathrm{C}$ for $2 \mathrm{~h}$. It was followed by monitoring the emission spectra of the solution using a spectrofluorometer. In a twostep method, TAMRA peptide $(2.5 \mu \mathrm{L}$ at $10 \mu \mathrm{M})$, MMP-7 (10 $\mu \mathrm{L}$ at different stock concentrations), and $20 \mathrm{mM}$ Tris buffer $(77.5 \mu \mathrm{L})$ were initially mixed and incubated at $37{ }^{\circ} \mathrm{C}$ for $2 \mathrm{~h}$, followed by the addition of AuNPs $(2.5$ or $5 \mu \mathrm{L}$ at $1 \mu \mathrm{M})$ and $\mathrm{NiCl}_{2}(10 \mu \mathrm{L}$ at $1 \mathrm{mM})$. After additional incubation at room temperature for $30 \mathrm{~min}$, the AuNP mixture was subjected to fluorescence scanning. Fluorescence intensity was normalized to the background intensity from the control solution without protease.

\section{Results and discussion}

To construct an efficient quenching system, peptide substrates comprising red dyes (TAMRA) at their N-termini and hexahistidines at their C-termini were mixed with carboxy AuNPs in the presence of $\mathrm{Ni}(\mathrm{II})$ ions (Scheme 1a). As a consequence, a dye-to-AuNP quenching was induced by a strong association between polyhistidine residues of the TAMRA peptide and the carboxy groups of the AuNPs via the coordination of $\mathrm{Ni}$ (II) metal ions (electron pair acceptors; Scheme 1b). Although common metal-chelating agents

a

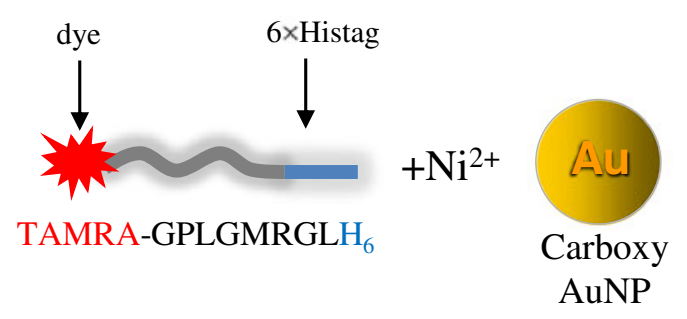

C

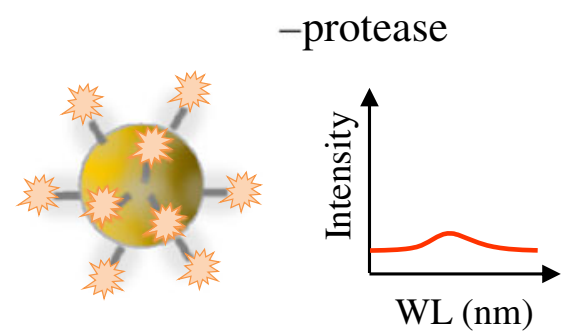

Scheme 1 a Schematic representation of the component of the AuNPdye conjugate for protease assay. $\mathbf{b}$ Schematic of the coordination of the $\mathrm{Ni}(\mathrm{II})$ ion with the histidines of peptides and the carboxyl groups on including NTA, iminodiacetic acid (IDA), carboxymethylated aspartic acid, and tris(carboxymethyl)ethylenediamine are available and being widely used for binding polyhistidine tag [39], the chelator-free metal affinity here can be achieved by only the surface-exposed carboxyl groups on the AuNPs. Since highly compacted carboxyl groups in the nanostructured surface can function like multidentate chelators, the binding affinity of Ni(II)-his-tagged carboxy AuNP is likely to be comparable to that of chelator-mediated conjugation (e.g., Ni(II)-his-tagged NTA; our unpublished data), which allowed for the higher quenching efficiency of the dye to AuNP due to their close proximity. In addition, site-specific conjugation and the simplicity of Ni(II)-histagged carboxy AuNP were further advantageous for protease assay. Based on this conjugation principle, fluorescence quenching and dequenching were strongly induced in the absence and the presence of protease, respectively (Scheme 1c, d).

The carboxy AuNPs were synthesized from citratestabilized AuNPs by conjugating carboxy-PEG-thiol and were characterized using a UV-Vis spectrophotometer and FETEM, which represented a strong surface plasmon resonance band near $520 \mathrm{~nm}$ and around $5 \mathrm{~nm}$ in diameter (Fig. 1). The extinction and fluorescent emission spectra of the TAMRA dye were also displayed in Fig. 1a. To check the quenching efficiency of the AuNP, different concentrations of the carboxy AuNPs, while maintaining the concentration of the
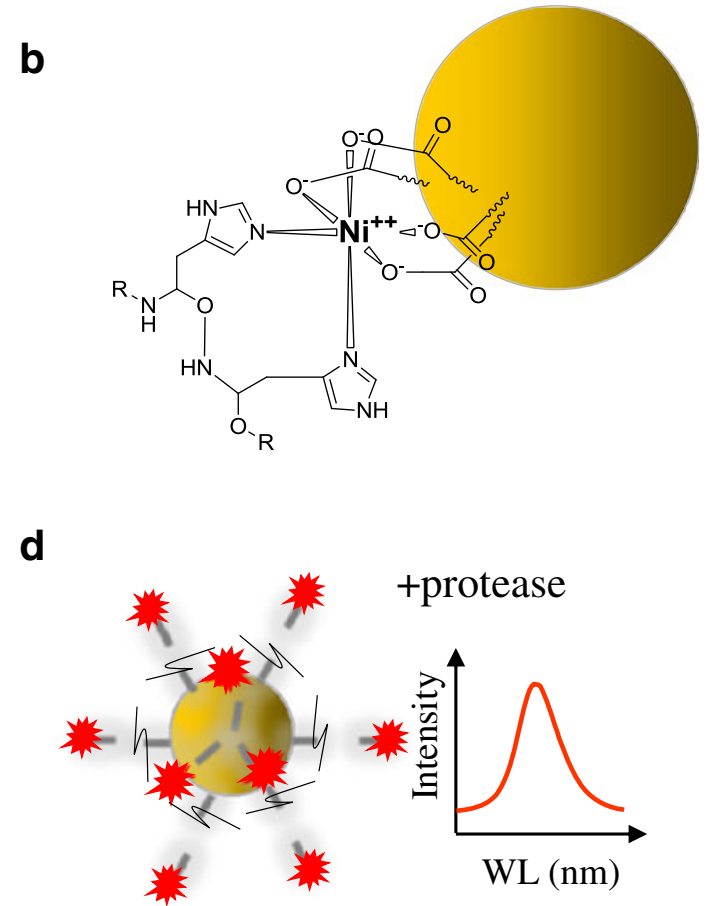

the AuNP. c Resultant fluorescence quenching. d Dequenching of the dye-conjugated AuNPs illustrated in the absence and the presence of protease 
Fig. 1 a Normalized extinction spectra of AuNPs (black solid) and the TAMRA dye (black dotted) and emission spectrum for the TAMRA dye (red dashed) showing considerable overlap of AuNP extinction and TAMRA emission. b Highresolution TEM image of carboxy AuNPs with a diameter of $5.1 \pm 1.4 \mathrm{~nm}(n=100)$

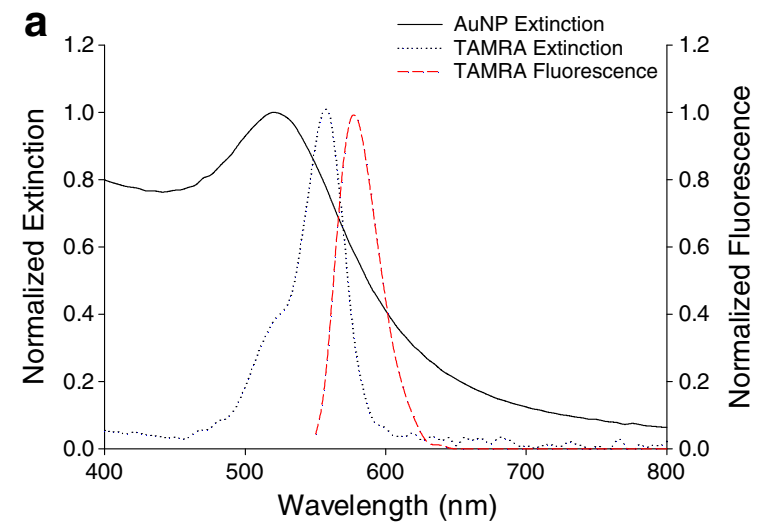

TAMRA peptide constant, were added to the TAMRA peptide Ni. As shown in Fig. 2a, the fluorescence intensity declined as the TAMRA-to-AuNP molar ratio decreased from 100:1 to 1:1 even in the absence of Ni. Since the amount of TAMRA was fixed at varied concentrations of AuNPs, the changes in fluorescence intensity were attributed to a quenching effect by the AuNPs. However, this result is probably due to a dynamic collisional quenching effect rather than an affinity-induced (TAMRA-GPLGMRGLH ${ }_{6}$ ) in the absence or the presence of

one because Ni-free TAMRA peptide can also be adsorbed on the AuNP by a diffusion-driven electrostatic interaction. In contrast, the addition of $\mathrm{Ni}$ facilitated a strong quenching effect by the proximate conjugation between the AuNP and dye, leading to a relatively large decrease in fluorescence intensity over all molar ratios (Fig. 2b). It was shown in Fig. 2c that the Ni(II) ion induced very effective quenching between the TAMRA peptide $\left(\mathrm{His}_{6}\right)$ and the carboxy AuNP (Fig. 2c) compared to the TAMRA dye without AuNPs.

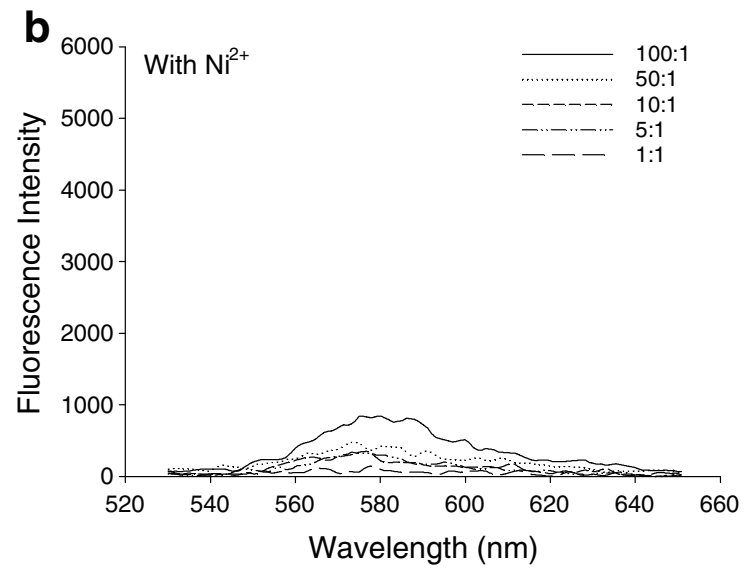

d

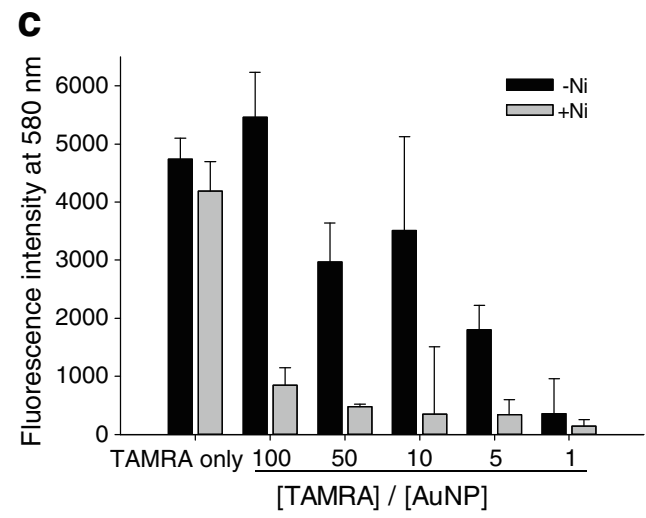

Fig. 2 Fluorescence spectra of the TAMRA peptide at different concentrations of AuNPs in the absence (a) or the presence (b) of Ni. The molar ratios of TAMRA to AuNP were varied from 100:1 to 1:1 (from top to bottom). c Maximal fluorescence intensities at $580 \mathrm{~nm}$ from (b)

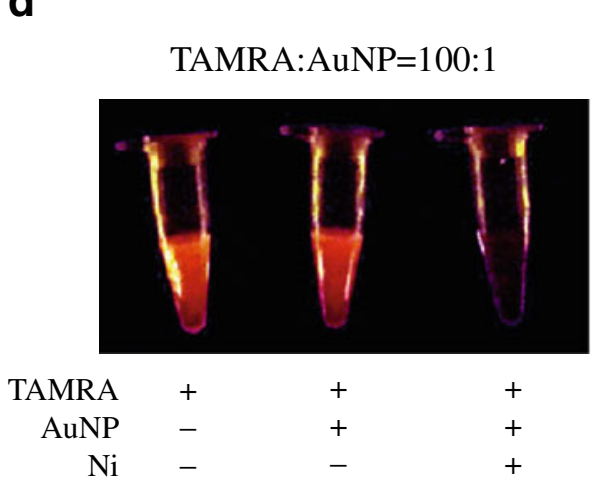

and (c) were compared as bar graphs in the absence or the presence of Ni. d Fluorescent images of the TAMRA peptide with and without AuNP or Ni 


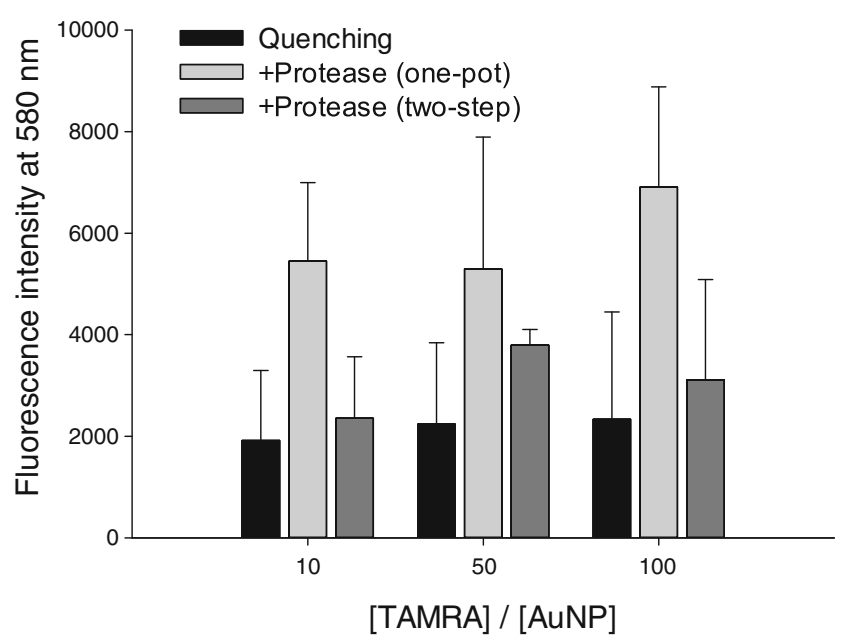

Fig. 3 Changes in the fluorescence intensities of the AuNP-quenched TAMRA conjugate before and after enzyme reaction at different molar ratios of TAMRA to AuNP. Protease reaction was performed in two methods: one-pot (light gray) and two-step reaction (dark gray). The enzyme (MMP-7) concentration was $1 \mu \mathrm{gmL}^{-1}$

Fluorescent images also represented the effect of $\mathrm{Ni}$ addition to the AuNP-based fluorescence quenching (Fig. 2d). This result strongly indicates that the his-tagged-dye and the carboxy AuNP were tightly associated via nickel coordination, giving rise to a higher fluorescence quenching. The quenching efficiency was calculated using the following equation: $100 \times\left(1-F_{\mathrm{Ni} / \mathrm{AuNP} \text { addition }} / F_{\mathrm{Ni} / \mathrm{AuNP}-\text { free }}\right)$, where $F_{\mathrm{Ni} /}$ AuNP addition is the fluorescence intensity of the TAMRA peptide in the presence of AuNP and Ni and $F_{\mathrm{Ni} / \mathrm{AuNP}-}$ free is the fluorescence intensity of the TAMRA peptide in the absence of AuNP and Ni. Particularly, the most significant difference in fluorescence intensity before and after the addition of $\mathrm{Ni}(\mathrm{II})$ ion was observed at a 100:1 ratio of TAMRA to AuNP, where the quenching

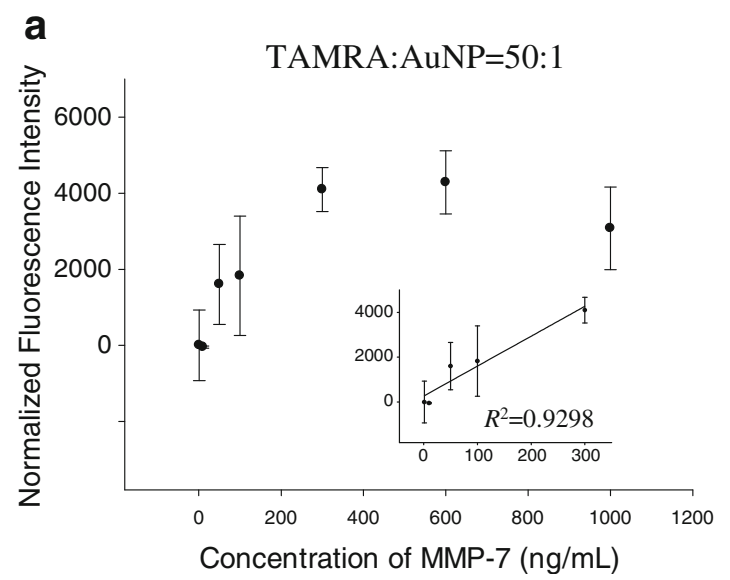

Fig. 4 Plot of the fluorescence intensity of the TAMRA peptide $\left(\mathrm{His}_{6}\right)$ / $\mathrm{Ni}(\mathrm{II}) / \mathrm{AuNP}$ as a function of MMP-7 concentration $\left(1-1,000 \mathrm{ng} \mathrm{mL}^{-1}\right)$ at different ratios of TAMRA/AuNP: 50:1 (a) and 100:1 (b). Peak intensities at $580 \mathrm{~nm}$ were normalized to the control set without MMP- efficiency is $82.2 \%$; in other cases, the corresponding quenching efficiencies were $90.0 \%$ for $50: 1,92.6 \%$ for $10: 1,92.8 \%$ for $5: 1$, and $96.9 \%$ for $1: 1$. It is worth noting that this quenching efficiency at a 100:1 ratio was much higher than that observed in the direct adsorption of rhodamine dye to the citrate-capped AuNPs [40], supporting the metal affinity interactions of carboxyl AuNPs in the present study.

To gain some insight into the dequenching effect by protease activity, enzyme reaction was attempted with varying ratios of the dye to AuNP in two different ways: a onepot reaction (all components were mixed at a time) and a two-step reaction (the TAMRA peptide initially reacted with the protease, followed by the addition of other components). MMP-7 was employed as a model protease. As shown in Fig. 3, a strong recovery of fluorescence intensity was observed for 10:1-100:1 quenched solutions by the onepot enzyme reaction, where the signal intensity increased by 2.8-fold (10:1), 2.4-fold (50:1), and 3.0 fold (100:1) to the quenching state (black and light gray bars in Fig. 3). Compared to that in Fig. 2c, the background intensity in Fig. 3 slightly increased after the quenched solution was subjected to the enzyme reaction condition $\left(2 \mathrm{~h}\right.$ at $\left.37^{\circ} \mathrm{C}\right)$. Importantly, the one-pot reaction was found to be much more efficient than the two-step reaction over the differing TAMAR-to-AuNP ratios, indicating that freely moving TAMRA peptide $\left(\mathrm{His}_{6}\right)$ in the initial step of the two-step method is expected to be either not much cleaved by the protease or induce high nonspecific binding to the AuNP after cleavage. It is postulated that the one-pot method enabled histidines to be captured initially by the carboxy AuNP in the presence of $\mathrm{Ni}^{2+}$, providing the optimal orientation and structural stability of the peptide-AuNP complex for protease reaction. Unlike the one-pot reaction, when the

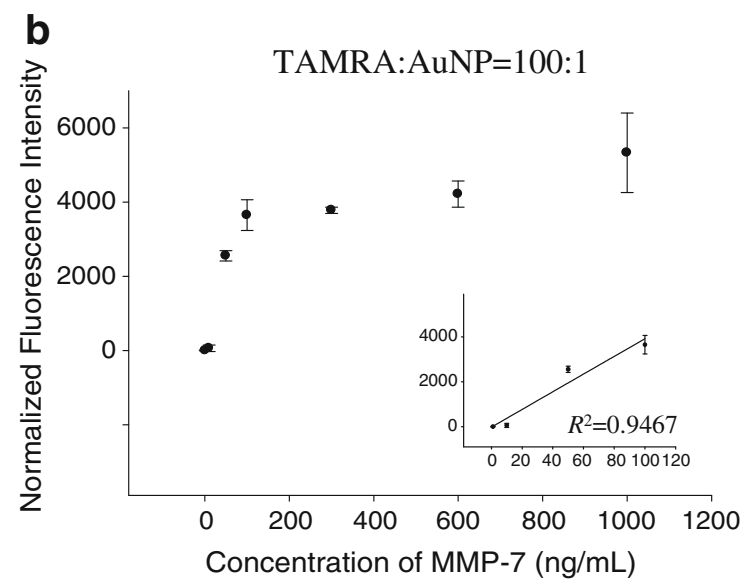

7. Error bars represent the standard deviation from two repeated experiments. The inset indicates the linearity between the fluorescence and MMP-7 concentration over the different dynamic ranges 
pre-quenched probe was subjected to the same enzyme reaction, no significant signal recovery was observed (data not shown). Despite the similarity in fluorescence recovery, in the case of 100:1, a high binding number and the close packing density of TAMRA peptides on the AuNP surface appear to allow the recovery yield to be slightly improved. These results suggest that the mixing type and timing between the AuNP reactant and enzyme would be very critical for the enzyme reaction, and the all-in-one reaction would be very suited to analyze the protease activity in terms of saving detection time.

To check for enzyme-dependent signal intensity in this system, the protease activity was monitored as a function of the MMP-7 concentration (Fig. 4). When the dequenching intensity was normalized to the control set in the absence of MMP-7, a hyperbolic curve was similarly observed both at a 50:1 (Fig. 4a) and at a 100:1 (Fig. 4b) ratio of the dye to AuNP, ranging from as low as 10 to $1,000 \mathrm{ngmL}^{-1}$ in terms of enzyme concentration. Although there was a slight decrease at a high concentration of MMP-7 in the case of a 50:1 ratio of dye to AuNP, the signal recovery showed a plateau after $300 \mathrm{ngmL}^{-1}$, which corresponds to approximately $70 \%$ of the maximum intensity of the TAMRA peptide displayed in Fig. 2a. This reveals that all of the peptides were not likely to be fully cleaved by MMP-7 at a high concentration. Additionally, there was a considerable linearity in the $50: 1\left(R^{2}=0.9298\right.$ for $\left.10-300 \mathrm{ngmL}^{-1}\right)$ and $100: 1$ ratios $\left(R^{2}=0.9467\right.$ for $\left.10-100 \mathrm{ngmL}^{-1}\right)$, where the 100:1 ratio condition showed a relatively improved sensitivity and reproducibility over the tested range based on the standard deviation. The detection sensitivity was comparable to those of other assay systems reported previously [22, 41]. Although the dynamic range seems to cover only one order range of the MMP-7 concentration, this result indicates that our developed system is well suited to detect the low concentration range of MMPs. While the AuNP-based colorimetric assay has been well developed [42], such AuNP-based fluorescence detection can offer greater sensitivity in terms of targeting DNA and proteins.

The AuNP-quenched strategy presented in this study has several advantages over the conventional dye-to-quencher system. In addition to the superior quenching effect of AuNPs, the simple and easy fabrication of fluorophoretethered peptides to the carboxy AuNPs via metal affinity can be achieved without requiring further complicated modifications of the AuNP by multidentate ligands, such as NTA and IDA. This strategy, therefore, enables fluorescent proteins fused to peptides and polyhistidine to be simply conjugated to the AuNP surface. Moreover, since the AuNPs can be generally employed as common quenchers, several fluorophores with different colors could be applied to the AuNPs for a multiplex assay with extremely low background signal.

\section{Conclusion}

In conclusion, we demonstrated the simple assay of protease activity using the AuNP-based fluorescence quenching system via metal affinity. Simple and rapid association between the carboxy groups of AuNPs and the hexahistidine regions of the dye-tethered peptides was observed in the presence of $\mathrm{Ni}(\mathrm{II})$ ions, leading to notable fluorescence quenching over varying molar ratios (100:1-1:1) of the dye to AuNP. When MMP-7 was added to the AuNP-dye solution, significant fluorescence dequenching was found, especially at 10:1100:1 dye-to-AuNP molar ratios, where the detection limit was as low as $10 \mathrm{ngm}^{-1}$. By combining fluorophores with different colors, this developed system will have great potential to study the protease activity with low background and high sensitivity.

Acknowledgment This work was supported by the Basic Science Research Program (2012-0008222), the Bio-Signal Analysis Technology Innovation Program (2012-0006053), and the Nano Material Technology Development Program (2012035286) through the National Research Foundation of Korea (NRF) funded by the Ministry of Education, Science and Technology.

Open Access This article is distributed under the terms of the Creative Commons Attribution License which permits any use, distribution and reproduction in any medium, provided the original author(s) and source are credited.

\section{References}

1. Dubertret B, Calame M, Libchaber AJ (2001) Single-mismatch detection using gold-quenched fluorescent oligonucleotides. Nat Biotechnol 19(7):680-681

2. Dulkeith E, Morteani AC, Niedereichholz T, Klar TA, Feldmann J, Levi SA, van Veggel FCJM, Reinhoudt DN, Moller M, Gittins DI (2002) Fluorescence quenching of dye molecules near gold nanoparticles: radiative and nonradiative effects. Phys Rev Lett 89(20):203002

3. Maxwell DJ, Taylor JR, Nie SM (2002) Self-assembled nanoparticle probes for recognition and detection of biomolecules. J Am Chem Soc 124(32):9606-9612

4. Rosi NL, Mirkin CA (2005) Nanostructures in biodiagnostics. Chem Rev 105(4):1547-1562

5. Bunz UHF, Rotello VM (2010) Gold nanoparticle-fluorophore complexes: sensitive and discerning "noses" for biosystems sensing. Angew Chem Int Edit 49(19):3268-3279

6. Acuna GP, Bucher M, Stein IH, Steinhauer C, Kuzyk A, Holzmeister P, Schreiber R, Moroz A, Stefani FD, Liedl T, Simmel FC, Tinnefeld P (2012) Distance dependence of single-fluorophore quenching by gold nanoparticles studied on DNA origami. ACS Nano 6(4):3189-3195

7. Sen T, Sadhu S, Patra A (2007) Surface energy transfer from rhodamine $6 \mathrm{G}$ to gold nanoparticles: a spectroscopic ruler. Appl Phys Lett 91(4):2762283

8. Yun CS, Javier A, Jennings T, Fisher M, Hira S, Peterson S, Hopkins B, Reich NO, Strouse GF (2005) Nanometal surface 
energy transfer in optical rulers, breaking the FRET barrier. J Am Chem Soc 127(9):3115-3119

9. Jennings TL, Singh MP, Strouse GF (2006) Fluorescent lifetime quenching near $d=1.5 \mathrm{~nm}$ gold nanoparticles: probing NSET validity. J Am Chem Soc 128(16):5462-5467

10. Kim JH, Estabrook RA, Braun G, Lee BR, Reich NO (2007) Specific and sensitive detection of nucleic acids and RNases using gold nanoparticle-RNA-fluorescent dye conjugates. Chem Commun 42:4342-4344

11. Obliosca JM, Wang PC, Tseng FG (2012) Probing quenched dye fluorescence of Cy3-DNA-Au-nanoparticle hybrid conjugates using solution and array platforms. J Colloid Interface Sci 371:34-41

12. Wang WJ, Chen CL, Qian MX, Zhao XS (2008) Aptamer biosensor for protein detection using gold nanoparticles. Anal Biochem 373 (2):213-219

13. Kim YP, Oh YH, Kim HS (2008) Protein kinase assay on peptideconjugated gold nanoparticles. Biosens Bioelectron 23(7):980-986

14. Mayilo S, Kloster MA, Wunderlich M, Lutich A, Klar TA, Nichtl A, Kurzinger K, Stefani FD, Feldmann J (2009) Long-range fluorescence quenching by gold nanoparticles in a sandwich immunoassay for cardiac troponin T. Nano Lett 9(12):4558-4563

15. Guirgis BSS, Cunha CSE, Gomes I, Cavadas M, Silva I, Doria G, Blatch GL, Baptista PV, Pereira E, Azzazy HME, Mota MM, Prudencio M, Franco R (2012) Gold nanoparticle-based fluorescence immunoassay for malaria antigen detection. Anal Bioanal Chem 402(3):1019-1027

16. Hu PP, Chen LQ, Liu C, Zhen SJ, Xiao SJ, Peng L, Li YF, Huang CZ (2010) Ultra-sensitive detection of prion protein with a long range resonance energy transfer strategy. Chem Commun 46 (43):8285-8287

17. Kim GB, Kim YP (2012) Analysis of protease activity using quantum dots and resonance energy transfer. Theranostics 2 (2): $127-138$

18. Lee H, Lee K, Kim IK, Park TG (2008) Synthesis, characterization, and in vivo diagnostic applications of hyaluronic acid immobilized gold nanoprobes. Biomaterials 29(35):4709-4718

19. Chen WY, Lan GY, Chang HT (2011) Use of fluorescent DNAtemplated gold/silver nanoclusters for the detection of sulfide ions. Anal Chem 83(24):9450-9455

20. Jin LH, Shang L, Guo SJ, Fang YX, Wen D, Wang L, Yin JY, Dong SJ (2011) Biomolecule-stabilized Au nanoclusters as a fluorescence probe for sensitive detection of glucose. Biosens Bioelectron 26(5):1965-1969

21. Huang Y, Zhao SL, Liang H, Chen ZF, Liu YM (2011) Multiplex detection of endonucleases by using a multicolor gold nanobeacon. Chem-Eur J 17(26):7313-7319

22. Kim YP, Oh YH, Oh E, Ko S, Han MK, Kim HS (2008) Energy transfer-based multiplexed assay of proteases by using gold nanoparticle and quantum dot conjugates on a surface. Anal Chem 80 (12):4634-4641

23. Swierczewska M, Lee S, Chen XY (2011) The design and application of fluorophore-gold nanoparticle activatable probes. Phys Chem Chem Phys 13(21):9929-9941

24. Welser K, Adsley R, Moore BM, Chan WC, Aylott JW (2011) Protease sensing with nanoparticle based platforms. Analyst 136 (1):29-41
25. Turk B (2006) Targeting proteases: successes, failures and future prospects. Nat Rev Drug Discov 5(9):785-799

26. Lowe SB, Dick JAG, Cohen BE, Stevens MM (2012) Multiplex sensing of protease and kinase enzyme activity via orthogonal coupling of quantum dot peptide conjugates. ACS Nano 6 (1):851-857

27. Mu CJ, LaVan DA, Langer RS, Zetter BR (2010) Self-assembled gold nanoparticle molecular probes for detecting proteolytic activity in vivo. ACS Nano 4(3):1511-1520

28. Free P, Shaw CP, Levy R (2009) PEGylation modulates the interfacial kinetics of proteases on peptide-capped gold nanoparticles. Chem Commun 33:5009-5011

29. Lee S, Cha EJ, Park K, Lee SY, Hong JK, Sun IC, Kim SY, Choi K, Kwon IC, Kim K, Ahn CH (2008) A near-infraredfluorescence-quenched gold-nanoparticle imaging probe for in vivo drug screening and protease activity determination. Angew Chem Int Edit 47(15):2804-2807

30. Hainfeld JF, Liu WQ, Halsey CMR, Freimuth P, Powell RD (1999) Ni-NTA-gold clusters target his-tagged proteins. J Struct Biol 127 (2):185-198

31. Swartz JD, Gulka CP, Haselton FR, Wright DW (2011) Development of a histidine-targeted spectrophotometric sensor using Ni(II)NTAfunctionalized $\mathrm{Au}$ and $\mathrm{Ag}$ nanoparticles. Langmuir 27(24):15330 15339

32. Hochuli E, Bannwarth W, Dobeli H, Gentz R, Stuber D (1988) Genetic approach to facilitate purification of recombinant proteins with a novel metal chelate adsorbent. Nat Biotechnol 6(11):13211325

33. Yao HQ, Zhang Y, Xiao F, Xia ZY, Rao JH (2007) Quantum dot/ bioluminescence resonance energy transfer based highly sensitive detection of proteases. Angew Chem Int Edit 46(23):4346-4349

34. Sternlicht MD, Werb Z (2001) How matrix metalloproteinases regulate cell behavior. Annu Rev Cell Dev Biol 17:463-516

35. Egeblad M, Werb Z (2002) New functions for the matrix metalloproteinases in cancer progression. Nat Rev Cancer 2(3):161-174

36. Page-McCaw A, Ewald AJ, Werb Z (2007) Matrix metalloproteinases and the regulation of tissue remodelling. Nat Rev Mol Cell Biol 8(3):221-233

37. Cumberland SL, Strouse GF (2002) Analysis of the nature of oxyanion adsorption on gold nanomaterial surfaces. Langmuir 18 (1):269-276

38. Lewis DJ, Day TM, MacPherson JV, Pikramenou Z (2006) Luminescent nanobeads: attachment of surface reactive Eu(III) complexes to gold nanoparticles. Chem Commun 13:1433-1435

39. Block H, Maertens B, Spriestersbach A, Brinker N, Kubicek J, Fabis R, Labahn J, Schafer F (2009) Immobilized-metal affinity chromatography (IMAC): a review. Method Enzymol 463:439-473

40. Stobiecka M, Hepel M (2011) Multimodal coupling of optical transitions and plasmonic oscillations in rhodamine B modified gold nanoparticles. Phys Chem Chem Phys 13(3):1131-1139

41. Kim YP, Oh YH, Oh E, Kim HS (2007) Chip-based protease assay using fluorescence resonance energy transfer between quantum dots and fluorophores. Biochip J 1(4):228-233

42. Wang LH, Zhang J, Wang X, Huang Q, Pan D, Song SP, Fan CH (2008) Gold nanoparticle-based optical probes for targetresponsive DNA structures. Gold Bull 41(1):37-41 